\title{
Access to Care for Methadone Maintenance Patients in the United States
}

\author{
Jennifer E. Hettema • James L. Sorensen
}

Received: 10 November 2008 / Accepted: 10 March 2009 /

Published online: 4 April 2009

C) The Author(s) 2009. This article is published with open access at Springerlink.com

\begin{abstract}
This policy commentary addresses a significant access to care issue that faces methadone maintenance patients seeking residential treatment in the United States. Methadone maintenance therapy (MMT) has demonstrated strong efficacy in the outpatient treatment of opiate dependence. However, many opiate dependent patients are also in need of more intensive interventions, such as residential care. Many publically-funded residential treatment programs explicitly decline to admit MMT patients, contending that methadone raises both clinical and administrative problems in treatment. Although advocates within the field believe that this issue is a violation of the American's with Disabilities Act (ADA) in the United States, no lawsuits have been brought forth, and there is no legal precedent or public policy to inform the debate. The present paper provides an overview of this problem and discusses factors that may contribute to the problem, including an abstinence-oriented philosophy and treatment program operational concerns. The paper also draws parallels between methadone and other medical conditions and analyzes the problem in the context of disabilities encompassed in the ADA. Finally, recommendations on strategies for increasing access to residential care for MMT patients are provided.
\end{abstract}

Keywords Methadone $\cdot$ Discrimination $\cdot$ Drug abuse $\cdot$ Drug treatment $\cdot$ Residential treatment

Opiate dependence is a major public health concern that contributes to a range of individual and social problems, including mortality, transmission of disease, psychopathology, and

J. E. Hettema

Department of Psychiatry and Neurobehavioral Sciences, University of Virginia, Charlottesville, USA

\section{J. L. Sorensen}

Department of Psychiatry and Neurobehavioral Sciences, University of Virginia, 1001 Potrero Avenue, San Francisco, CA 94110, USA

\section{J. L. Sorensen}

San Francisco General Hospital, Department of Psychiatry, University of California San Francisco, San Francisco, USA

J. E. Hettema $(\bowtie)$

University of Virginia, 2821 North Parham Road, Suite 203, Richmond, VA 23294, USA

e-mail: jhettema@virginia.edu 
criminality (Teeson et al. 2006). Methadone maintenance therapy (MMT) has highly demonstrated efficacy at reducing illicit opiate use (Gossop et al. 2003) and improving overall psychosocial functioning, including employment, criminal activity, and contraction of HIV/AIDS. In the United States, there are approximately 1,396 MMT programs serving over 254,000 patients (SAHMSA 2006).

MMT patients receive limited services as part of their opioid replacement treatment, including medical screening, dosing, and outpatient counseling. However, for many patients, a higher level of care is necessary to deal with their opiate addiction or other comorbid disorders. Consequently, many MMT patients seek out a higher level of care at residential treatment programs.

For opiate-dependent patients receiving MMT, the adage "more is better" seems to be supported by research. For example, delivery of more treatment services within the context of methadone treatment has been found to lead to better outcomes, with those receiving a higher number of services showing greater improvements, even after controlling for patient factors (Gossop et al. 2003). This study found that "treatment dose," as measured by number of days in treatment, number of treatment sessions attended, and number of services received, was predictive of positive outcome.

Evidence also seems to suggest that patients with previous methadone treatment may differentially benefit from residential treatment. For example, Cheung and Ch'ien (1999) found that patients who participated in methadone treatment prior to residential treatment were five times more likely to be abstinent from heroin at a three year follow-up point. The authors interpreted the findings to suggest that participation in methadone programs may facilitate successful outcome in residential treatment and that a compatible relationship between the harm reduction and abstinence oriented approaches to treatment may be possible.

Despite the effectiveness and widespread use of MMT, and the demonstrated benefit of combining MMT with other more intensive forms of treatment, integration remains a controversial topic. In fact, many substance abuse treatment providers assert that MMT is incompatible with recovery and the abstinence-based treatment models of most residential treatment programs. Methadone maintenance program staff have reported years of frustration in trying to obtain residential treatment services for their MMT patients, as many state-licensed and publicly funded residential treatment programs have policies in place that explicitly deny access to care for MMT patients (Zweben et al. 1999). This paper is not intended to an exhaustive critique of access to care issues for MMT patients, but proposes to focus on several key factors that may contribute to access to care problems in the United States, offer several arguments in favor of increasing access to care, and provide some practical recommendations for increasing access to care for this population.

\section{Contributing Factors}

Multiple factors likely contribute to the current status of residential treatment for MMT patients in the United States. Although systems level factors such as the limited availability of residential treatment and insurance/payment issues probably play an important role, this section will focus on the impact of two key factors, including the impact of the abstinenceoriented philosophy that is commonly espoused with residential treatment programs and the operational concerns that face residential treatment programs who extend treatment services to MMT patients. 
Impact of Abstinence-Oriented Philosophy

Until the last several decades, the evolution of substance abuse treatment occurred largely in isolation from scientific study or traditional medical care (Miller et al. 2006). Mainstream society and the medical field viewed addictions as moral problems of the will, rather than valid medical disorders, and consequently devoted few resources to scientifically investigate effective treatments. As a result, substance abuse treatment emerged largely in the form of treatment by compassionate peers, who were themselves in recovery. This peerled perspective has generally been strongly influenced by viewpoints that complete abstinence is the only route to recovery and that many medications, including methadone, merely enable individuals to maintain addictive lifestyles. This viewpoint is also widely held in society at large, in which abstinence models tend to evoke more support than methadone. Zweben and Sorensen (1988) pointed out that American society regards methadone as a "necessary evil" and believe that "patients should use the least possible amount," an adage that is unsupported by research. With the rise of behavioral research in the last several decades, we now have a variety of empirically evaluated treatment approaches that do not follow an abstinence-oriented philosophy. Yet abstinence models of recovery, still have a dominant influence, especially in residential treatment facilities.

The use of abstinence-oriented models, such as Alcoholics Anonymous, has been found to benefit patients who electively choose to participate in such programs, but not those who are coerced to participate (Kownacki and Shadish 1999). Despite this, abstinence-oriented treatment philosophies have become integrated into a variety of other treatment modalities, including many residential treatment programs.

Providers who hold an abstinence-based view of recovery have been found to be less receptive to the dissemination of evidence-based practices and to rely more heavily on testimonial evidence and personal experience when making clinical decisions (Miller et al. 2006). These tendencies may have contributed to the bias against MMT that often exists within residential treatment programs. Decades of misinformation within these abstinenceoriented programs and lack of receptivity to evidence demonstrating effectiveness have created a stigma against the use of methadone in recovery. This stigma, in turn, has resulted in the denial of treatment services to MMT within many residential treatment programs.

\section{Treatment Program Operational Concerns}

Residential treatment programs often have treatment philosophies contending that abstinence from all substances is necessary for "true" recovery, and these beliefs about the correct path to recovery are commonly cited as the reason for denying treatment to MMT patients. However, Zweben et al. (1999) also describe some practical operational concerns that may serve to prevent equal access to care. As they describe, "residential programs vary widely in their sophistication, and some have little or no experience in dealing with medication and related matters" (Zweben et al. 1999, pp.250). Consequently, these programs may feel unable to adequately address issues such as safe storage, monitoring patient dosage, and collaborating with physicians and methadone programs.

While much of the stigma against the use MMT does not seem grounded in evidence, some important arguments against the integration of MMT and residential treatment have been put forth. Residential treatment programs are faced with a complex context for their clinical decision making (Zemore and Kaskutas 2008). Unlike methadone clinics, in which the behavior of one client has little effect on others, patients within residential treatment programs are highly dependent on one another. Here the behavior of one individual can 
have a huge effect on the overall environment and, consequently, what may be beneficial to one client may be harmful to the community as a whole.

Some residential treatment providers argue that the many frequent trips to the methadone clinic that are often required for appropriate dosing can significantly interfere with the residential treatment process. For one, providing transportation to and from methadone clinics can be timely, expensive, or impractical for residential staff. In addition, an important component of residential treatment programs is that they are designed to help patients sever ties to negative influences in their outside environment. Frequent trips to the methadone clinic have been argued to provide patients with many potentially dangerous opportunities to maintain these bonds. MMT clients who have to leave the site to get dosed may also miss important group activities, interfering with assimilation into the community, and sometimes making non-MMT clients feel that they receiving special privileges. The "nodding out" behavior, or abruptly falling asleep during sedentary activity, that is sometimes associated with methadone treatment has also been cited as potentially disruptive to groups. One last potential complication of integrating the two forms of treatment is the ability of residential programs to securely store and distribute take-home doses of methadone.

\section{Arguments in Support of Increasing Access to Care}

While research has demonstrated that residential treatment improves the treatment prognosis of MMT patients, there are several other compelling reasons to increase access to care for this population. Drawing parallels between MMT patients and patients with other medical conditions may help to alleviate potential bias against this group by adding historical perspective to the debate. In addition, denial of treatment may be a violation of the Americans with Disabilities Act, which is aimed at providing equal opportunities for individuals with physical and mental disabilities, including substance use disorders.

\section{Parallels to Other Conditions}

Although the participation of MMT patients in residential treatment raises some potential concerns, the obstacles are not unlike what one might expect for an individual with another medical condition, such as epilepsy (Grunfeld and Komlodi 2006). Here too, the individual would require frequent trips to a health care provider and possibly be prescribed anticonvulsants with side effects of drowsiness. In addition, little controversy can be found within the literature regarding the appropriateness of residential treatment for individuals with other medical disorders, suggesting that stigma and differences in treatment philosophy are a driving force of denial of treatment services to MMT patients. Greenberg et al. (2007) point out that there was similar ideological contention years ago, when psychiatric medications were first being utilized in addiction treatment centers, but now psychiatric medications are seen as the standard of care for patients with co-occurring disorders. In addition, at least two published articles have demonstrated that the potential barriers to integration of MMT and residential treatment can be successfully overcome with appropriate staff training and collaboration between sites (Zweben et al. 1999; Sorensen et al. 2009).

Americans with Disabilities Act Implications

Limitations in access to care for MMT patients hinder these patients from obtaining needed substance abuse and mental health treatment services. While differences in norms regarding 
effective treatments and practical considerations may serve as barriers, collaboration between residential treatment and methadone programs would ultimately increase access to evidence-based care for MMT patients.

Issues of disability have special salience for MMT patients (Benoit et al. 2004) who are commonly denied services as a result of their use of prescribed medications for the treatment of their substance dependence. In fact, many interpret the denial of residential treatment services as a violation of the Americans with Disabilities Act (ADA; Zweben et al. 1999). However, the ADA can be interpreted to inform the denial of treatment services to MMT patients in several ways.

The ADA (1990) is an American civil rights law that prevents discrimination based on disability. The law was enacted in 1990 as protects individuals with disability from discrimination in areas such as employment and receipt of public services. The ADA defines disability as "a physical or mental impairment that substantially limits one or more of the major life activities of such individual." Under this definition, an individual with substance dependence is considered a qualified individual with a disability. One caveat to this definition is that a qualified individual with a disability shall not include individuals who are engaging in the illegal use of drugs. However, the definition of illegal use of drugs does not include the use of drugs taken under the supervision of a licensed health care professional, as is the case with prescribed methadone. Section 302 of the ADA prohibits discrimination by health care providers in the form of denial of participation in services. Here the imposition or application of eligibility criteria that screen out individuals with a disability is considered discrimination. This section can be interpreted as clearly prohibiting the denial of residential treatment services to opiate dependent MMT. However, the ADA also specifies that denial of services on the basis of disability is not considered discrimination in the case that making such accommodations would fundamentally alter the nature of the service or would result in an undue burden. This section can be interpreted to exempt denial of treatment to MMT patients from the label of discrimination, by arguing that allowing MMT to participate in abstinence based treatment would fundamentally alter the nature of the treatment program and compromise the recovery of other treatment participants.

While discrimination against individuals taking prescribed medications through the denial of treatment may be a violation of the ADA, the authors are aware of no litigation that has yet been brought forth to establish legal precedence with regard to methadone within residential treatment. In addition, as yet there are no legislative policies or licensing regulations in place that address equal access to care for MMT patients.

\section{Discussion and Recommendations}

It was the purpose of the present paper to increase awareness of this access-to-care issue, explain both sides of the argument, and provide a rationale for improving access to care for MMT patients. It should be acknowledged however, that this paper is far from a comprehensive evaluation of access to care issues that face MMT patients. The paper focuses on several important factors that may contribute to the present access to care inequities and offers several arguments in favor of increasing access to care. The paper is also limited to examples from the United States and research and discussion would be further enhanced by examining additional perspectives.

In the paper, we aimed to demonstrate that access to residential treatment would clearly benefit MMT patients. While no legal precedence has been established regarding the implications of MMT patients' access to care, a solution in which MMT patients can 
receive residential treatment without fundamentally altering the treatment experience of other patients would be optimal. Greenberg et al. (2007) suggest several practical strategies that may improve the feasibility of methadone within residential treatment, including educating staff about methadone to eliminate misconceptions and reduce staff generated stigma. In addition, the authors recommend preparing staff to deal with difficult situations regarding methadone, including jealousy from other patients and nodding off behaviors. The authors also recommend educating other patients on methadone related topics and facilitating twelve-step oriented MMT groups within the program.

A remaining issue is whether the treatment models used in medically-oriented methadone programs and abstinence-oriented therapeutic communities are so incompatible that they cannot be combined effectively. Cherry (2008) points out that philosophical differences can so deeply divide mental health and addiction services that it is impractical to integrate them. While further research is needed on this topic, Sorensen et al. (2009) recently completed a trial that found similar outcomes of residential treatment for matched MMT and non-MMT patients. In the trial, MMT patients were found to have residential treatment and substance abuse outcomes that were no different than their non-MMT counterparts, painting an optimistic picture of the possibility of equal access to residential care for MMT patients.

Acknowledgments Supported in part by grants from Robert Wood Johnson Foundation and the National Institutes of Health (R01-DA14922, U10-DA015815, P50-DA09253, R01 AA015930, R01 AA14356, R01 DA016554, and T32DA07250).

Open Access This article is distributed under the terms of the Creative Commons Attribution Noncommercial License which permits any noncommercial use, distribution, and reproduction in any medium, provided the original author(s) and source are credited.

\section{References}

Americans with Disabilities Act of 1990. (1991). Pub. L. No. 101-336, §2, 104 Stat. 328.

Benoit, E., Young, R., Magura, S., \& Staines, G. L. (2004). The impact of welfare reform on methadone treatment: policy lessons from service providers in New York City. Substance Use and Misuse, 39, 2355-2390. doi:10.1081/JA-200034643.

Cherry, A. (2008). Mixing oil and water: integrating mental health and addiction services to treat people with co-occurring disorders. International Journal of Mental Health and Addiction, 6, 407-420. doi:10.1007/ s11469-007-9074-8.

Cheung, Y. W., \& Ch'ien, J. M. (1999). Previous participation in outpatient methadone program and residential treatment outcome: a research note from Hong Kong. Substance Use and Misuse, 34, 103118. doi:10.3109/10826089909035638.

Gossop, M., Duncan, S., \& Marsden, J. (2003). Treatment process components and heroin use outcome among methadone patients. Drug and Alcohol Dependence, 71, 93-102. doi:10.1016/S0376-8716(03) 00067-X.

Greenberg, B., Hall, D. H., \& Sorensen, J. L. (2007). Methadone maintenance therapy in residential therapeutic community settings: challenges and promise. Journal of Psychoactive Drugs, 39, 203-210.

Grunfeld, A., \& Komlodi, S. J. (2006). The stigmatization of neurological and mental health conditions: epilepsy as a case example. International Journal of Mental Health and Addiction, 4, 85-86. doi:10.1007/s11469-006-9018-8.

Kownacki, R. J., \& Shadish, W. R. (1999). Does alcoholics anonymous work? The results from a metaanalysis of controlled experiments. Substance Use and Misuse, 34, 1897-1916. doi:10.3109/ 10826089909039431. 
Miller, W. R., Sorensen, J. L., Selzer, J. A., \& Brigham, G. S. (2006). Disseminating evidence-based practices in substance abuse treatment: a review with suggestions. Journal of Substance Abuse Treatment, 31, 25-39. doi:10.1016/j.jsat.2006.03.005.

SAMHSA. (2006). National survey of substance abuse treatment services. Found at: http://wwwdasis. samhsa.gov/webt/state_data/US06.pdf.

Sorensen, J. L., Andrews, S., Delucchi, K. L., Greenberg, B., Guydish, J., Masson, C. L., et al. (2009). Methadone patients in the therapeutic community: a test of equivalency. Drug and Alcohol Dependence, 100(1), 100-109. doi:10.1016/j.drugalcdep. 2008.09.009.

Teeson, M., Ross, J., Drake, S., Lynskey, M., Ali, R., Ritter, A., et al. (2006). One year outcomes for heroin dependence: findings from the Australian Treatment Outcome Study (ATOS). Drug and Alcohol Dependence, 83, 174-180. doi:10.1016/j.drugalcdep. 2005.11.009.

Zemore, S. E., \& Kaskutas, L. A. (2008). Services received and treatment outcomes in day-hospital and residential programs. Journal of Substance Abuse Treatment, 35, 232-244. doi:10.1016/j. jsat.2007.10.006.

Zweben, J. E., \& Sorensen, J. L. (1988). Misunderstandings about methadone. Journal of Psychoactive Drugs, 20, 275-281.

Zweben, J. E., Aly, T., Martin, J., Wengrofsky, S., Bacci, J., \& Meddaugh, R. (1999). Making residential treatment available to methadone clients. Journal of Substance Abuse Treatment, 17, 249-256. 